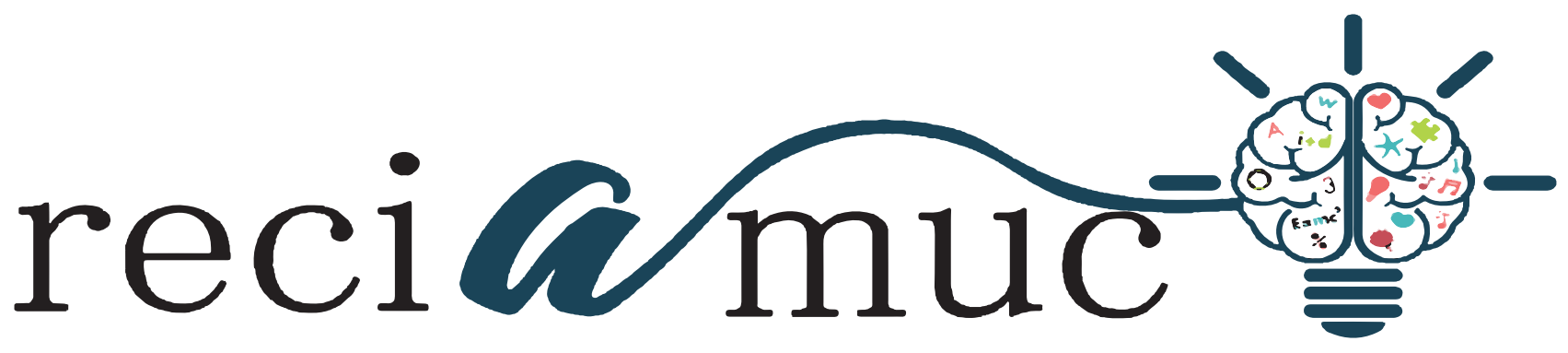

DOI: 10.26820/reciamuc/5.(4).noviembre.2021.118-128

URL: https://reciamuc.com/index.php/RECIAMUC/article/view/735

EDITORIAL: Saberes del Conocimiento

REVISTA: RECIAMUC

ISSN: 2588-0748

TIPO DE INVESTIGACIÓN: Artículo de Revisión

CóDIGO UNESCO: 32 Ciencias Médicas

PAGINAS: $118-128$

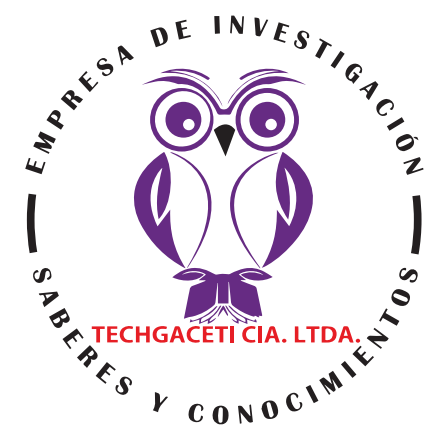

\title{
Infección por virus de inmunodeficiencia humana
}

Human immunodeficiency virus infection Infecção pelo vírus da imunodeficiência humana

\section{Karen Michelle Cabrera Dutan'; Wilson Andrés Cabrera Dutan2; Andrea Nicole Ordóñez Ortiz3; Darwin Rolando Pinchao Obando ${ }^{4}$}

RECIBIDO: 15/09/2021 ACEPTADO: 05/10/2021 PUBLICADO: 29/11/2021

1. Médico Cirujano; Investigador Independiente; Santo Domingo, Ecuador; karencita_mcd@hotmail.com; (D) https://orcid.org/0000-0002-3917-8573

2. Médico General; Investigador Independiente; Santo Domingo, Ecuador; wandres_1991@hotmail.com; (DD https://orcid.org/0000-0003-4978-9826

3. Médico General; Investigador Independiente; Guayaquil, Ecuador; andrea-25042014@hotmail.com; (DD https:// orcid.org/0000-0002-8474-4415

4. Médico General; Investigador Independiente; Tulcán, Ecuador; darwin_0820@hotmail.com; (D) https://orcid. org/0000-0002-5059-0542

\section{CORRESPONDENCIA}

Karen Michelle Cabrera Dutan

karencita_mcd@hotmail.com

Santo Domingo, Ecuador

() RECIAMUC; Editorial Saberes del Conocimiento, 2021 


\section{RESUMEN}

La epidemia del Virus de Inmunodeficiencia Humana $(\mathrm{VIH})$ no es un fenómeno actual, sino que viene desde hace ya varios años, específicamente desde la década de los 80 , cuando se detectaron los primeros casos en seres humanos. Desde entonces se calcula que 79.3 millones de personas contrajeron el virus desde que comenzó la epidemia. EI VIH es el virus que causa el Síndrome de Inmunodeficiencia Adquirida (SIDA). Cuando una persona se infecta con VIH, el virus ataca y debilita al sistema inmunitario. A medida que el sistema inmunitario se debilita, la persona está en riesgo de contraer infecciones y cánceres que pueden ser mortales. El tratamiento del VIH implica tomar medicamentos que reducen la cantidad de virus que hay en el cuerpo. Estos medicamentos se llaman terapia antirretroviral (TAR). No hay ninguna cura eficaz para la infección por el $\mathrm{VIH}$, pero con la atención médica adecuada, puede ser controlada. Una persona puede reducir el riesgo de infección limitando su exposición a los factores de riesgo y tomando medidas preventivas como el uso de preservativos masculinos y femeninos, pruebas de detección y asesoramiento en relación con el VIH y las ITS, uso de antirretrovíricos a modo de prevención, reducción de daños en los consumidores de drogas inyectables, eliminación de la transmisión del VIH de la madre al niño, entre otras. El enfoque general del presente trabajo es abordar los aspectos más relevantes de la Infección por Virus de Inmunodeficiencia Humana (VIH). Los resultados se obtuvieron mediante el desarrollo de una investigación de tipo bibliográfica, delimitada a una metodología de revisión, que permite concluir que la infección por VIH continúa siendo un problema de salud pública de primer orden en el mundo, tanto por su magnitud y evolución temporal como por sus consecuencias sanitarias, sociales y económicas. Por ello es tan importante el diagnóstico y tratamiento precoces, que son la estrategia preventiva más eficiente.

Palabras clave: Virus, inmunodeficiencia, VIH, SIDA, retroviral, infección.

\section{ABSTRACT}

The Human Immunodeficiency Virus (HIV) epidemic is not a current phenomenon, but has been going on for several years now, specifically since the 1980s, when the first cases were detected in humans. Since then, an estimated 79.3 million people have contracted the virus since the epidemic began. HIV is the virus that causes Acquired Immune Deficiency Syndrome (AIDS). When a person becomes infected with HIV, the virus attacks and weakens the immune system. As the immune system weakens, the person is at risk for infections and cancers that can be fatal. HIV treatment involves taking medicines that reduce the amount of virus in the body. These drugs are called antiretroviral therapy (ART). There is no effective cure for HIV infection, but with proper medical care, it can be controlled. A person can reduce the risk of infection by limiting their exposure to risk factors and taking preventive measures such as the use of male and female condoms, HIV and STI screening and counseling, use of antiretrovirals for prevention, harm reduction in injection drug users, elimination of transmission of HIV from mother to child, among others. The general approach of this work is to address the most relevant aspects of Human Immunodeficiency Virus (HIV) Infection. The results were obtained through the development of a bibliographic research, limited to a review methodology, which allows to conclude that HIV infection continues to be a first-order public health problem in the world, both due to its magnitude and temporal evolution as well as its health, social and economic consequences. For this reason, early diagnosis and treatment are so important, as they are the most efficient preventive strategy.

Keywords: Virus, immunodeficiency, HIV, AIDS, retroviral, infection.

\section{RESUMO}

A epidemia do Vírus da Imunodeficiência Humana (HIV) não é um fenômeno atual, mas já se arrasta há vários anos, especificamente desde a década de 1980, quando os primeiros casos foram detectados em humanos. Desde então, cerca de 79,3 milhões de pessoas contraíram o vírus desde o início da epidemia. HIV é o vírus que causa a Síndrome da Imunodeficiência Adquirida (AIDS). Quando uma pessoa é infectada pelo HIV, o vírus ataca e enfraquece o sistema imunológico. À medida que o sistema imunológico enfraquece, a pessoa corre o risco de desenvolver infecções e cânceres que podem ser fatais. O tratamento do HIV envolve o uso de medicamentos que reduzem a quantidade de vírus no corpo. Esses medicamentos são chamados de terapia antirretroviral (TARV). Não há cura eficaz para a infecção pelo HIV, mas com cuidados médicos adequados, ela pode ser controlada. Uma pessoa pode reduzir o risco de infecção limitando sua exposição a fatores de risco e tomando medidas preventivas, como o uso de preservativos masculinos e femininos, HIV e IST e aconselhamento, uso de anti-retrovirais para prevenção, redução de danos em usuários de drogas injetáveis, eliminação de transmissão do HIV da mãe para o filho, entre outros. A abordagem geral deste trabalho é abordar os aspectos mais relevantes da infecção pelo vírus da imunodeficiência humana (HIV). Os resultados foram obtidos por meio do desenvolvimento de uma pesquisa bibliográfica, limitada a uma metodologia de revisão, que permite concluir que a infecção pelo HIV continua sendo um problema de saúde pública de primeira ordem no mundo, tanto pela sua magnitude e evolução temporal quanto. suas consequências para a saúde, sociais e econômicas. Por esse motivo, o diagnóstico e o tratamento precoces são tão importantes, pois são a estratégia preventiva mais eficaz.

Palavras-chave: Vírus, imunodeficiência, HIV, AIDS, retroviral, infecção. 


\section{Introducción}

La epidemia del Virus de Inmunodeficiencia Humana (VIH) no es un fenómeno actual, sino que viene desde hace ya varios años, específicamente desde la década de los 80, cuando se detectaron los primeros casos en seres humanos. Desde entonces se calcula que 79.3 millones de personas contrajeron el virus desde que comenzó la epidemia. (Vivas, 2021).

I número de víctimas mortales del VIH/ SIDA desde esa década no es concreto, pero se tiene certeza que ronda entre los 27,2 millones y los 47,8 millones. La ONUSIDA detalla que de los 37.7 millones de personas que viven en la actualidad con $\mathrm{VIH}$, 36 millones son adultos y 1.7 millones son niños hasta los 14 años. El 53\% en general son mujeres y niñas. Otro dato a destacar es que aproximadamente 6.1 millones de personas no sabían que estaban viviendo con el VIH en 2020. Mientras que el 84\% restante si conocían su estado serológico, lo que representa un pequeño avance en comparación con el 2019. (Vivas, 2021).

El VIH es definido por Pimentel (2016) como un retrovirus caracterizado por infectar las células del sistema inmunitario (principalmente las células T CD4+ y los macrófagos, componentes clave del sistema inmunitario celular). Cuando no es controlada con drogas antirretrovirales, la infección por este virus deteriora el sistema inmunitario en forma gradual.

El Síndrome de Inmunodeficiencia Adquirida (SIDA) es la forma más grave de la infección provocada por el virus de la inmunodeficiencia humana (VIH). En este particular Fernández \& García (2018) refieren que:

Se denomina síndrome porque el SIDA consiste en la aparición de una o diversas enfermedades. Estas enfermedades se desarrollan porque el virus provoca la destrucción lenta, continua y progresiva de una parte del sistema encargado de la defensa del organismo, el sistema inmunitario. El
VIH no puede vivir fuera del organismo durante mucho tiempo y, por este motivo, para que se transmita hace falta un contacto físico directo con la persona infectada, siendo las vias de transmision mas comunes la vía sexual y la vía sanguínea. (Fernández \& García, 2018).

El tratamiento farmacológico en el que se combinan tres o más fármacos antirretrovirales, aunque no cura la infección, frena la replicación del virus en el organismo y permite que el sistema inmunitario recobre fortaleza y capacidad para combatir las infecciones. Reyes et al. (2020).

La OMS en el 2016 recomendó de por vida el TARV a todas las personas infectadas por este virus. Es así que entre los objetivos para minimizar los efectos de la epidemia del VIH en el mundo, propuesto por el Programa Conjunto de las Naciones Unidas sobre el VIH/SIDA (Onusida), que espera, para el 2030 que el $90 \%$ de las personas que viven con $\mathrm{VIH}$ conozcan su estado serológico respecto a este virus, que el $90 \%$ de las personas diagnosticadas con sida reciban terapia antirretroviral continua y el $90 \%$ de las personas que reciben terapia antirretrovírica tengan supresión viral. Por lo que la supresión vírica se considera una herramienta fundamental en la prevención del avance de infección del VIH y está claramente relacionada con la adherencia al tratamiento. (p. 4).

Según Basany et al. (2019) las personas portadoras del VIH deben tener hábitos de vida saludables para no contraer otras infecciones, indicando algunas recomendaciones, como:

- Lavarse las manos con frecuencia y siempre que haya habido situaciones de mayor probabilidad de contaminación, como después de ir al servicio.

- Evitar el contacto con pacientes con infecciones agudas activas.

- Estar al día con las vacunaciones. 
- Seguir un estilo de vida saludable, sin tabaco ni drogas, y practicar ejercicio físico.

El objetivo de este trabajo investigativo, desarrollado bajo un diseño documental, se centra en realizar una revisión a la literatura científica disponible, que principalmente aborde la Infección por Virus de Inmunodeficiencia Humana, su definición, principales factores de riesgo, métodos de diagnóstico y tratamiento, y medidas de prevención, todo ello con la finalidad de proporcionar un material actualizado que defina dichos aspectos y que sea de utilidad no solo para el personal de salud, sino también para el público en general.

\section{Materiales y Métodos}

El presente trabajo de investigación, enmarcado en una metodología de revisión, está orientado a la construcción de un material bibliográfico actualizado, enfocado en dar a conocer los criterios vigentes de la Infección por Virus de Inmunodeficiencia Humana $(\mathrm{VIH})$.

Entre las bases de datos consultadas destacan: La Organización Mundial de la Salud (OMS), Biblioteca Virtual de la Salud (BVS), Mayo Clinic, entre otras. Como términos de búsqueda se utilizaron las expresiones "Infección por Virus de Inmunodeficiencia Humana (VIH)" y "Síndrome de Inmunodeficiencia Adquirida (SIDA)", y se aplicaron criterios de selección tales como: idioma español e inglés; publicación entre 2016 y 2021 (ambos inclusive); acceso completo y abierto; en el área de salud y medicina; estudios referidos a humanos; tipo de bibliografía, manuales médicos, guías clínicas, ensayos clínicos, estudios o reportes de casos, boletines y/o folletos de instituciones oficiales o privadas de excelente trayectoria en el área de la salud, medicina o científico académica, y demás, monografías y otros documentos que, a criterio propio, mostraran información de interés en base a la observación de la evidencia científica referida en sus contenidos. Este proceso arrojó resultados que en promedio oscilaron entre 6 y 89 enlaces a fuentes de información bibliográficas.

De igual manera fueron adelantados otras sondeos menores sin considerar la aplicación de cualquier otro criterio de descarte, ya que se requirió encontrar información complementaria que independientemente de su origen o época de publicación, es considerada igualmente importante ajustada y de relevancia para este tema. Es a partir de entonces que se procedió con la lectura crítica y análisis interpretativo de un pilar de información recopilado a lo largo de la investigación, que también fue adoptada como evidencia. Resultando todo este proceso en la selección de los elementos más sustanciales y significativos de las diferentes fuentes bibliográficas que fundamentan el razonamiento aquí expuesto.

\section{Resultados}

El virus de inmunodeficiencia humana $(\mathrm{VIH})$ es el virus que causa el Síndrome de Inmunodeficiencia Adquirida (SIDA). Cuando una persona se infecta con VIH, el virus ataca y debilita al sistema inmunitario. A medida que el sistema inmunitario se debilita, la persona está en riesgo de contraer infecciones y cánceres que pueden ser mortales. (Enciclopedia Médica A.D.A.M., 2020).

Una vez que una persona tiene el virus, este permanece dentro del cuerpo de por vida. El sistema inmunitario de una persona con sida ha sido dañado por el VIH. Estas personas tienen un riesgo muy alto de contraer infecciones que son poco frecuentes en personas con un sistema inmunitario saludable. Estas infecciones se denominan oportunistas. Pueden ser causadas por bacterias, virus, hongos o protozoos y pueden afectar cualquier parte del cuerpo. Las personas con sida también tienen un riesgo más alto de padecer ciertos tipos de cáncer, especialmente linfomas y un tipo de cáncer de piel llamado sarcoma de Kaposi. (Enciclopedia Médica A.D.A.M., 2020). 
El Centro para el Control y Prevención de Enfermedades (CDC) (2021) indica que la infección por el VIH en los seres humanos provino de un tipo de chimpancé de África Central.

La versión del virus en los chimpancés (llamado virus de inmunodeficiencia símica o VIS) se pudo haber transmitido a los seres humanos cuando cazaban a los chimpancés por los por su carne y entraron en contacto sangre infectada. Los estudios muestran que el VIH pudo haber pasado de los chimpancés a los seres humanos ya a finales de los años 1800. El virus se propagó lentamente por toda África a lo largo de varias décadas y, luego, a otras partes del mundo. (Centro para el Control y Prevención de Enfermedades (CDC), 2021).

La Organización Mundial de la Salud (OMS) (2021) señala que el VIH, que continúa siendo uno de los mayores problemas para la salud pública mundial, se ha cobrado alrededor de 36,3 millones de vidas.

Se calcula que a finales de 2020 había 37,7 millones de personas que vivían con el $\mathrm{VIH}$, más de dos tercios (25,4 millones) en la Región de África. Ese mismo año, 680.000 personas murieron por causas relacionadas con el VIH y 1,5 millones de personas resultaron infectadas por el virus. (Organización Mundial de la Salud (OMS) , 2021).

La infección por VIH es definida por Cachay (2019) como un trastorno vírico que, progresivamente, destruye ciertos glóbulos blancos (leucocitos) y puede causar el Síndrome de Inmunodeficiencia Adquirida (SIDA).

Esta infección puede estar causada por uno de dos retrovirus: el VIH-1 o el VIH-2. EI VIH1 causa la mayoría de las infecciones por $\mathrm{VIH}$ en todo el mundo, pero el VIH-2 causa muchas infecciones por VIH en África Occidental. Cuando el VIH entra en una célula humana, libera su ARN, y una enzima llamada transcriptasa inversa hace una copia en ADN del ARN del VIH. El ADN del VIH obtenido de este modo se integra en el ADN de la célula infectada. Este proceso es el inverso del utilizado por las células humanas, que crean una copia de ARN a partir del ADN. Por lo tanto, el VIH es lo que se conoce como un retrovirus, haciendo referencia a dicho proceso inverso. El VIH se adhiere a las células $T$ del huésped y penetra en ellas a través de la mediación de moléculas CD4+ y receptores de quimiocina. Después de la adhesión, el RNA y varias de las enzimas codificadas por el HIV se liberan dentro de la célula huésped. (Cachay, 2019).

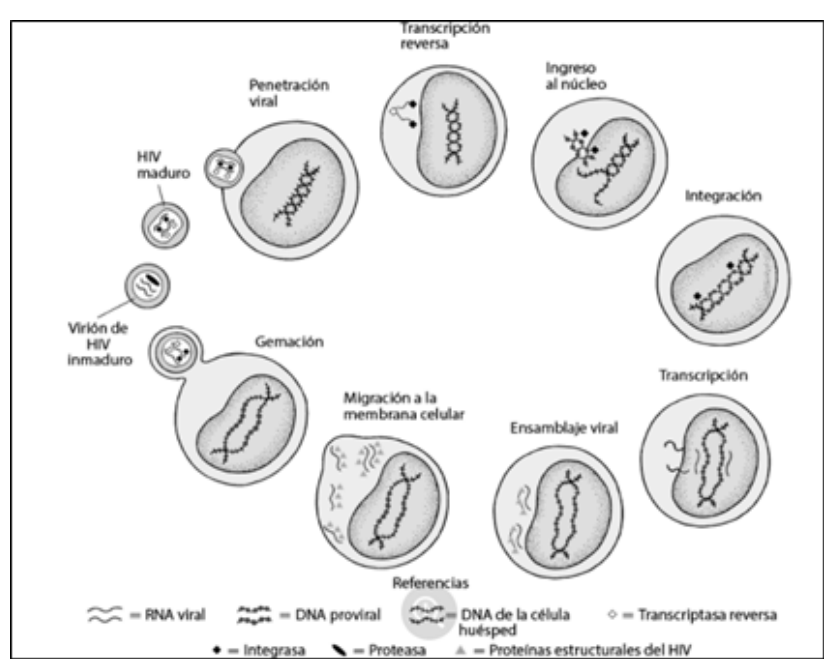

Figura 1. Ciclo vital simplificado del HIV.

Fuente: Infección por el virus de inmunodeficiencia humana (HIV). Cachay (2019) Manual MSD.

Recuperado de: https://www.msdmanuals.com/es-ve/professional/enfermedades-infecciosas/virus-de-inmunodeficiencia-humana-hiv/ infecci\%C3\%B3n-por-el-virus-de-inmunodeficiencia-humana-hiv

Cuando las personas que tienen el VIH no reciben tratamiento, la infección generalmente pasa por tres fases de progresión. Las cuales son descritas por los Centros para el Control y Prevención de Enfermedades (CDC) (2021), según sigue:

Fase 1: Infección aguda por el VIH:

- Las personas tienen una gran cantidad 
de $\mathrm{VIH}$ en la sangre. Son muy contagiosas.

- Algunas personas tienen síntomas similares a los de la influenza. Esta es la respuesta natural del cuerpo a la infección. Pero puede que algunas personas no se sientan enfermas inmediatamente o en absoluto.

- Solo se puede diagnosticar con las pruebas de antígenos y anticuerpos, o con las pruebas de ácido nucleico (NAT).

Fase 2: Infección crónica por el VIH

- La fase de infección crónica por el VIH también se llama fase de infección asintomática o de latencia clínica.

- Durante esta fase, el virus sigue estando activo, pero se reproduce a niveles muy bajos.

- Durante esta fase las personas podrían no presentar ningún síntoma ni sentirse enfermas.

- La fase puede durar una década o más si no se toman medicamentos para el $\mathrm{VIH}$, pero en algunas personas la progresión puede ser más rápida.

- Durante la fase de infección crónica se puede transmitir el $\mathrm{VIH}$.

- Al final de esta fase, aumenta la cantidad del VIH en la sangre (la cual se llama carga viral) y se reduce el recuento de células CD4. A medida que van aumentando los niveles de virus en el cuerpo y la infección va progresando a la fase 3, las personas pueden presentar síntomas.

- Las personas que toman los medicamentos para el VIH según las indicaciones podrían no llegar nunca a la fase 3 .

Fase 3: Síndrome de inmunodeficiencia adquirida (SIDA)

- El síndrome de inmunodeficiencia ad- quirida es la fase más grave de la infección por el VIH.

- Las personas con SIDA tienen el sistema inmunitario tan dañado que comienzan a tener una cantidad cada vez mayor de enfermedades graves, las cuales se llaman infecciones oportunistas.

- Las personas reciben el diagnóstico de SIDA cuando sus recuentos de células CD4 caen por debajo de 200 células/ $\mathrm{mm}$ o cuando comienzan a presentar ciertas infecciones oportunistas.

- Las personas con SIDA pueden tener niveles de carga viral elevados y ser muy contagiosas.

- Sin tratamiento, las personas con SIDA sobreviven aproximadamente tres años, por lo general.

Cualquier persona de cualquier edad, raza, sexo u orientación sexual puede estar infectada con el VIH/SIDA. Sin embargo, según Mayo Clinic (2020) el mayor riesgo de contraer el VIH/SIDA se da cuando:

- Se tienen relaciones sexuales sin protección. Usar un nuevo preservativo de látex o poliuretano cada vez que se tengan relaciones sexuales. El sexo anal es más riesgoso que el sexo vaginal. El riesgo de contraer el VIH aumenta si se tienen múltiples parejas sexuales.

- Se tiene una infección de transmisión sexual. Muchas infecciones de transmisión sexual producen llagas abiertas en los genitales. Estas Ilagas actúan como entradas del $\mathrm{VIH}$ al cuerpo.

- Se usan drogas intravenosas. Las personas que consumen drogas intravenosas suelen compartir agujas y jeringas. Esto los expone al contacto con gotas de sangre de otras personas.

López et al. (2018) define el Síndrome de Inmunodeficiencia Adquirida (SIDA), como una enfermedad infecto contagiosa producida por el Virus de Inmunodeficiencia Hu-

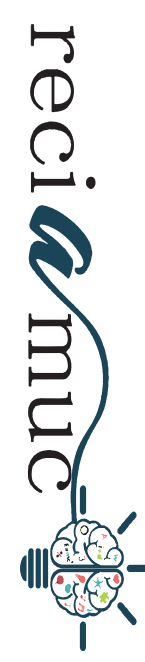


mana $(\mathrm{VIH})$, que ataca el sistema de defensa de la persona, haciéndola susceptible a contraer cualquier enfermedad y causarle la muerte. Las vías de transmisión que se han demostrado son las siguientes:

Transmisión Sexual. Esta vía es la más frecuente donde se contrae el virus a través de la actividad sexual sin protección, siendo el sexo anal y vaginal los más riesgosos, aunque se señala que existe un pequeño número que va en aumento de casos reportados de transmisión del VIH por el medio del sexo oral. Con cada una de estas prácticas la pareja receptiva está en mayor riesgo. En sexo heterosexual, las mujeres corren mayor peligro de infectarse que los hombres, estas vías de infección por contacto sexual tanto en las relaciones anales, vaginales y buco genitales son las que cobran mayor número de víctimas. Es muy frecuente en hombres que tienen sexo con otros hombres.

- Transmisión Sanguínea. El VIH cuando se transmite por vía sanguínea, se vehiculiza a través de transfusiones de sangre y hemoderivados. También se puede transmitir al compartir jeringas o agujas para inyectarse drogas, las personas que comparten las mismas pueden transmitir el virus en pequeñas cantidades de sangre que queden en la aguja o jeringa usada, pues, el uso común de jeringas es muy frecuente en los usuarios de drogas intravenosas. En el caso de la transfusión sanguínea o componentes hay abundantes pruebas que indican que la sangre y los productos hematológicos o el concentrado del factor VIII obtenidos de pacientes con SIDA Ileven el agente causal, sin embargo, para que se transmita es necesario que la sangre infectada se introduzca directamente al torrente sanguíneo del receptor, que puede ser favorecida por pinchazos o heridas producidas por agujas u objetos que pinchen o corten y que hayan estado en contacto con sangre infectada.
- Transmisión Perinatal. En la transmisión transplacentaria y/o perinatal se transmite de la madre al hijo en el embarazo, parto y lactancia. La transmisión se efectúa por distintos medios en relación al momento del contagio. Durante el embarazo se produce a través de la placenta. En el parto la rotura de la bolsa amniótica y el traumatismo del canal favorecen el contacto del feto con las secreciones genitales maternas. Si la madre está infectada y hay contacto directo de sus secreciones o de su sangre con mucosas y sangre fetal, la transmisión se efectúa en esta etapa. Durante la asistencia del parto las madres seropositivas, cuando en la ligadura y sección del cordón umbilical se exprime la sangre hacia el hijo, se aumenta la posibilidad de infectar al recién nacido. En el posparto la transmisión del HIV se efectúa frecuentemente mediante la leche materna, durante la lactancia.

Los síntomas del VIH y del SIDA varían de una persona a otra. Sin embargo, Rowden (2021) los diferencia de la siguiente manera:

- Síntomas del VIH: fiebre y escalofríos, sudores nocturnos, dolores musculares, sarpullidos, dolor de garganta, fatiga general, ganglios linfáticos inflamados y úlceras bucales.

- Síntomas del SIDA: pérdida rápida de peso, sudores nocturnos fuertes, fiebres continuas, fatiga extrema, cansancio inexplicable, inflamación prolongada de los ganglios linfáticos en la ingle, el cuello o las axilas, episodios de diarrea que duran más de una semana, llagas cerca de la boca, los genitales o el ano, neumonía, manchas en o debajo de la piel, manchas dentro de la boca, la nariz o los párpados, pérdida de la memoria, depresión, otros trastornos neurológicos.

De acuerdo a lo indicado por Álvarez (2017) el uso de pruebas de laboratorio es indis- 
pensable para el diagnóstico de la infección por $\mathrm{VIH}$, sin embargo, estas pruebas no permiten determinar si el individuo se encuentra en el estadio del síndrome de inmunodeficiencia adquirida (SIDA). Entre las pruebas para el diagnóstico, este autor señala:

- Pruebas de Tamizaje: Las de primera línea son las de tamizaje, se caracterizan por tener una buena sensibilidad. Entre ellas menciona las siguientes:

1. Pruebas rápidas: A pesar de ser exámenes de diversa metodología y diferente capacidad diagnóstica, tienen ciertas características en común: su tiempo de ejecución es de 20 minutos o menos, no necesitan equipamiento (pueden realizarse fuera del laboratorio) y tienen incorporados sistemas de control de calidad interno.

2. ELISA: Se caracterizan por una alta sensibilidad, cercana al 100\%, y una buena especificidad (99,5\%) que aún es superior a la de las pruebas rápidas e inferior a la de las confirmatorias. La especificidad depende de la calidad del antígeno que contiene la prueba, que es el componente que define su generación; actualmente sólo son aceptables los ELISA de tercera y cuarta generación.

3. Antigenemia p24: Es una prueba altamente específica pero su sensibilidad no es óptima, presentando falsos negativos; limitándose su uso al diagnóstico precoz durante el periodo de ventana, cuando hay signos clínicos de primoinfección o presunción de exposición. Por ello se ha preferido incorporarla a los ELISA de cuarta generación.

4. Quimioluminiscencia: Es un método automatizado basado en el principio de emisión luminosa a través de una reacción enzima-sustrato; es más sensible que los ELISA, por eso un resultado no reactivo es más confiable, y es muy específico. Los resultados reactivos deben corroborarse mediante las pruebas confirmatorias; los débilmente reactivos 0 dudosos deben repetirse y si persisten así, para efectos prácticos, se considerarán reactivos.

Pruebas confirmatorias: Cuando los resultados de las pruebas de tamizaje determinan un diagnóstico presuntivo de infección por VIH, se recurrirá a las pruebas confirmatorias que se caracterizan por su alta especificidad, superior a todas las de tamizaje. Actualmente se emplean tres:

- Inmunofluorescencia indirecta: Tiene una sensibilidad y especificidad similar al WB, incluso su positividad puede ocurrir antes que el WB, es mucho más barata (de 10 a 11 veces menor), su tiempo de ejecución es menor y la técnica más simple; por ello ha desplazado al WB. Su positividad constituye diagnóstico definitivo de la infección por el VIH y la negatividad, en general, también es definitiva de no infección, excepto cuando existe evidencia de exposición reciente y reiterada, en tales circunstancias se recomienda repetir el ensayo luego de tres y seis meses respectivamente.

- Western Blot: Es una prueba altamente específica pero, por su alto costo se emplea básicamente para corroborar los resultados indeterminados de la IFI. El resultado positivo confirma definitivamente la infección por el VIH; el negativo la descarta, excepto cuando existe evidencia de exposición reciente y reiterada a esta infección. En tales circunstancias se debe repetir el ensayo luego de tres y seis meses respectivamente. Cuando el resultado es indeterminado, que ocurre cuando sólo aparecen algunas bandas que no cumplen con los criterios del CDC, se recomienda repetir la prueba después de tres y seis meses, dependiendo de los factores de riesgo identificables en cada caso.

- Line Immuno Assay (LIA): Su empleo está menos difundido que la IFI y el WB, 
su performance es superior a este último e incluso se le considera el estándar de oro. Una vez confirmada la infección por el VIH recién se procederá a efectuar las pruebas pronosticas (recuento de linfocitos CD4 y carga viral).

Tabla 1. Pruebas diagnósticas directas e indirectas para la infección por el virus de la inmunodeficiencia humana

\begin{tabular}{|ll|}
\hline \multicolumn{1}{|c|}{ Pruebas indirectas } & \multicolumn{1}{c|}{ Pruebas directas } \\
\hline $\begin{array}{l}\text { Pruebas rápidas Ac } \\
\text { ELISA de tercera generación } \\
\text { Quimioluminiscencia } \\
\text { Inmunofluorescencia } \\
\text { indirecta } \\
\text { Western Blot }\end{array}$ & $\begin{array}{l}\text { Antigenemia p24 } \\
\text { Pruebas rápidas Ag/AC } \\
\text { Line ammuno assay }\end{array}$ \\
\hline
\end{tabular}

Fuente: Interpretación de las pruebas usadas para diagnosticar la infección por virus de la inmunodeficiencia humana. Álvarez (2017). Acta Médica Peruana. 34(4). Pág. 311.

Recuperado de: http://www.scielo.org.pe/pdf/amp/v34n4/a09v34n4.pdf

El Centro para el Control y Prevención de Enfermedades (CDC) (2021) indica que el tratamiento del VIH implica tomar medicamentos que reducen la cantidad de virus que hay en el cuerpo. Los medicamentos para el VIH se Ilaman terapia antirretroviral (TAR). No hay ninguna cura eficaz para la infección por el VIH, pero con la atención médica adecuada, puede ser controlada.

En este mismo sentido Mayo Clinic (2020) señala que la terapia antirretroviral suele ser una combinación de tres o más medicamentos de varias clases de fármacos diferentes. Normalmente se utilizan dos fármacos de una clase, más un tercer fármaco de una segunda clase. Las clases de fármacos contra el VIH incluyen:

- Los inhibidores de la transcriptasa inversa no análogos de nucleósidos (ITINN) bloquean una proteína que el VIH necesita para replicarse. Entre los ejemplos se incluyen el efavirenz (Sustiva), la rilpivirina (Edurant) y la doravirina (Pifeltro).

- Los inhibidores de la transcriptasa inversa análogos de nucleósidos o nucleótidos (ITIN) son versiones defectuosas de los componentes básicos que el VIH necesita para replicarse. Entre los ejemplos se incluyen el abacavir (Ziagen), el tenofovir (Viread), la emtricitabina (Emtriva), la lamivudina (Epivir) y la zidovudina (Retrovir). También se dispone de fármacos combinados, como la emtricitabina/tenofovir (Truvada) y la emtricitabina/tenofovir alafenamida (Descovy).

- Los inhibidores de la proteasa (IP) inactivan la proteasa del VIH, otra proteína que el VIH necesita para replicarse. Entre los ejemplos se incluyen el atazanavir (Reyataz), el darunavir (Prezista) y el lopinavir/ritonavir (Kaletra).

- Los inhibidores de la integrasa funcionan inhibiendo a una proteína llamada integrasa que el VIH utiliza para insertar su material genético en los linfocitos $T$ CD4. Entre los ejemplos figuran el bictegravir sódico/emtricitabina/tenofovir alafenamida fumarato (Biktarvy), raltegravir (Isentress) y dolutegravir (Tivicay).

- Los inhibidores de entrada o fusión bloquean la entrada del VIH en los linfocitos T CD4. Algunos ejemplos son la enfuvir- 
tida (Fuzeon) y el maraviroc (Selzentry).

Una persona puede reducir el riesgo de infección por el VIH limitando su exposición a los factores de riesgo. La Organización Mundial de la Salud (OMS) (2021) explica los principales métodos para prevenir el contagio:

- Uso de preservativos masculinos y femeninos.

- Pruebas de detección y asesoramiento en relación con el $\mathrm{VIH}$ y las ITS.

- Pruebas de detección y asesoramiento para vínculos con el tratamiento de la tuberculosis.

- Circuncisión médica masculina voluntaria.

- Uso de antirretrovíricos a modo de prevención.

- Reducción de daños en los consumidores de drogas inyectables.

- Eliminación de la transmisión del VIH de la madre al niño.

\section{Conclusión}

La infección por el Virus de Inmunodeficiencia Humana $(\mathrm{VIH})$ continúa siendo un problema de salud pública de primer orden en el mundo, tanto por su magnitud y evolución temporal como por sus consecuencias sanitarias, sociales y económicas. Por ello es tan importante el diagnóstico y tratamiento precoces, que son la estrategia preventiva más eficiente.

\section{Bibliografía}

Álvarez, R. (10 de 2017). Interpretación de las pruebas usadas para. Acta Medica de Peru, 34(4), 309316. Recuperado el 05 de 11 de 2021, de http:// www.scielo.org.pe/pdf/amp/v34n4/a09v34n4.pdf

Basany, E., Hernandez, M., \& Biondo, S. (29 de 11 de 2019). Tu Canal de Salud. Recuperado el 09 de 11 de 2021, de Tu Canal de Salud: https://www. tucanaldesalud.es/es/tusaludaldia/articulos/prevenir-transmision-virus-vih
Cachay, E. (08 de 2019). Manual Merck. Recuperado el 04 de 11 de 2021, de Manual Merck: https://www. merckmanuals.com/es-us/hogar/infecciones/ infecci\%C3\%B3n-por-el-virus-de-la-inmunodeficiencia-humana-vih/infecci\%C3\%B3n-por-el-virus-de-la-inmunodeficiencia-humana-vih

Centro para el Control y Prevención de Enfermedades (CDC). (07 de 06 de 2021). Centro para el Control y Prevención de Enfermedades (CDC). Recuperado el 08 de 11 de 2021, de Centro para el Control y Prevención de Enfermedades (CDC): https://www.cdc.gov/hiv/spanish/basics/whatishiv. html

Enciclopedia Médica A.D.A.M. (15 de 06 de 2020). MedlinePlus. Recuperado el 05 de 11 de 2021, de MedlinePlus: https://medlineplus.gov/spanish/ ency/article/000594.htm

Fernández, E., \& García, F. (20 de 02 de 2018). Clinica Barcelona. Recuperado el 09 de 11 de 2021, de Clinica Barcelona: https://www.clinicbarcelona. org/asistencia/enfermedades/vih-sida/definicion

López, V., Troya, G., Varas, N., \& Guzman, M. (30 de 10 de 2018). Algunas consideraciones sobre el VIH/SIDA. Revista Científica Mundo de la Investigación y el Conocimiento, 2(4), 48-69. doi:10.26820/ recimundo/2.(4).octubre.2018.48-69

Mayo Clinic. (13 de 02 de 2020). Mayo Clinic. Recuperado el 08 de 11 de 2021, de Mayo Clinic: https://www.mayoclinic.org/es-es/diseases-conditions/hiv-aids/symptoms-causes/syc-20373524

Organización Mundial de la Salud (OMS) . (17 de 07 de 2021). Organización Mundial de la Salud (OMS) - Recuperado el 08 de 11 de 2021, de Organización Mundial de la Salud (OMS) : https://www.who. int/es/news-room/fact-sheets/detail/hiv-aids

Pimentel, Z. (2016). Virus de Inmunodeficiencia Humana (VIH) en el trabajo, sometimiento frente. Salud de los Trabajadores, 24(2), 145-148. Recuperado el 09 de 11 de 2021, de https://www.redalyc. org/pdf/3758/375851163009.pdf

Reyes, L., Campo, E., Espinosa, A., Granados, A., \& Gil, I. (2020). Adherencia al tratamiento antirretroviral en personas con VIH/sida de la región Caribe - colombiano. Revista Cubana de Higiene y Epidemiología, 57(29), 1-16. Recuperado el 04 de 11 de 2021, de http://www.revepidemiologia.sld.cu/ index.php/hie/article/view/295/1051 
Rowden, A. (17 de 03 de 2021). Medical News Today. Recuperado el 04 de 11 de 2021, de Medical News Today: https://www.medicalnewstoday.com/ articles/es/sintomas-del-vih
Vivas, M. (11 de 10 de 2021). Consultor Salud. Recuperado el 08 de 11 de 2021, de Consultor Salud: https://consultorsalud.com/estadisticas-mundiales-sobre-el-vih-2020/

\section{CITAR ESTE ARTICULO:}

Cabrera Dutan, K. M., Cabrera Dutan, W. A., Ordóñez Ortiz, A. N., \& Pinchao Obando, D. R. (2021). Infección por virus de inmunodeficiencia humana. RECIAMUC, 5(4), 118-128. https://doi.org/10.26820/reciamuc/5.(4).noviembre.2021.118-128

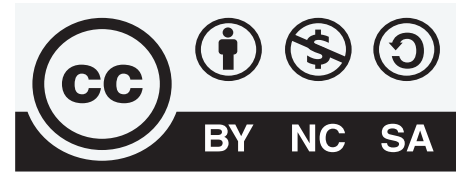

CREATIVE COMMONS RECONOCIMIENTO-NOCOMERCILL-COMPARTIRIOUAL 4.0. 